\title{
RESENHA
}

\section{PASSAGEIROS DA NOITE: DO TRABALHO PARA A EJA: ITINERÁRIOS PELO DIREITO A UMA VIDA MAIS JUSTA}

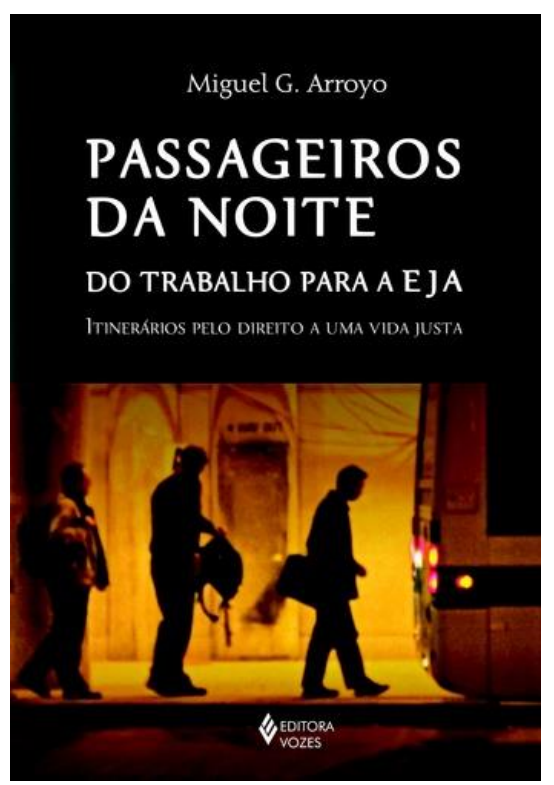

Marisa Narcizo Sampaio(*)

"Paulo Freire nos advertia que qualquer saber que não se alimenta de novas perguntas torna-se algo morto"(ARROYO, 2017, p.256). Esta afirmação, embora esteja no final do mais recente livro de Miguel Arroyo, Passageiros da Noite : do trabalho para a EJA : itinerários pelo direito a uma vida mais justa, publicado pela Vozes em 2017, parece guiar seu texto provocador, repleto de perguntas e questionamentos que instigam a pensar e fazer formação de jovens e adultos, sejam eles educadores ou educandos.

Provocações próprias de quem, como Miguel Arroyo, sempre esteve engajado em causas populares e movimentos sociais, fazendo deles tema e motivo de suas pesquisas e de sua profícua produção acadêmico-científica que há muitos anos serve de orientação para discussão e estudo de gerações de educadores e educadoras, nos ensinando o que aprender com esses movimentos, suas experiências e suas lutas por direitos humanos e vida digna.

Neste livro ele nos apresenta os sujeitos da EJA como passageiros de itinerários diversos rumo ao direito à educação e a uma vida mais justa. Entende estes deslocamentos, emblemáticos para esta população, como formativos. Observa adolescentes, jovens e adultos educandos nas filas para o transporte que os leva do trabalho para a educação e pergunta: quem são estes estudantes passageiros da noite? Como entender seus percursos? Com que olhar exigem ser olhados?

Pode-se responder a esta pergunta da forma como a elite, a mídia e até o pensamento pedagógico hegemônico veem estes sujeitos e respondem: selvagens, violentos, desordeiros, sem valores, sem cultura, sem lei, iletrados, inconscientes e incivilizados. O livro, no entanto, aposta em outra resposta: são passageiros à procura de um viver menos indigno, menos injusto. São sujeitos periféricos, vítimas da segregação social, espacial, racial, de gênero, política, cultural, mas são também sujeitos de luta, saberes, valores, justiça, dignidade, de consciência de si e do mundo, e do

\footnotetext{
${ }^{(*)}$ Professora do Centro de Educação da Universidade Federal do Rio Grande do Norte (UFRN).
} 
seu direito à vida justa. Haverá lugar nos currículos que garantam seu direito de saberem-se?, é uma pergunta transversal no texto.

Arroyo defende que para saberem-se como tal, os educandos precisam de seus companheiros de passagem e de esperança: mestres-docentes que tenham formação problematizadora. Por isso, voltando-se para os educadores, pergunta: como olhar esses itinerários? O que aprender com eles? Com que artes pedagógicas trabalhar com eles? Que respostas inventar? Para dar respostas a estas perguntas são necessários outros currículos, outro projeto pedagógico, outros tratos, outros olhares, outros mestres-educadores, outra EJA, que reconheçam os jovens e adultos por serem sujeitos de direitos e não por suas carências, que compreendam a radicalidade de seus percursos humanos e sociais.

Ao afirmar que a vida dos educandos e sua condição de segregados sociopolíticos, econômicos e culturais interrogam radicalmente o pensamento pedagógico e a docência, Arroyo dá à formação docente a responsabilidade de compreender e problematizar esta condição e de promover o diálogo entre mestres e educandos sobre como se veem, como se pensam, como se inquietam nestes percursos.

Dessa forma, a ideia do ser passageiro é retomada constantemente como forma de compreender a condição dos adolescentes, jovens e adultos e de seus mestres-educadores, todos sujeitos da EJA. Que parte dos primeiros está nos segundos? Educandos e educadores são continuamente aproximados: são sujeitos da educação pública periférica; muitas vezes ambos têm a EJA como última opção; são trabalhadores vítimas da negação de direitos trabalhistas que se deslocam pela cidade ou campo a educação porque nela acreditam

Que conhecimentos garantirão a educadores e educandos saberem-se trabalhadores de lutas pelo direito ao trabalho?

Assim, apostando, como sempre, no processo educativo como humanizador e libertador, e na EJA como educação que acontece em diversos contextos, dentro e fora da escola, Arroyo propõe que os mesmos temas, que se referem à vida dos educandos, componham o currículo de formação tanto dos educadores e como dos educandos. A partir deles levanta questões e as estabelece como objeto de discussão para a formação dos docentes, de maneira que estes compreendam os percursos dos educandos e criem formas de trabalhar para que eles também problematizem sua própria vida, e compreendam-se como sujeitos de direitos. 
Não será tarefa dos cursos de Pedagogia e Licenciatura onde se formam professores entender os processos de desumanização e tentar encontrar conhecimentos a que os jovens e adultos têm direito para saberem-se sujeitos com direito a uma vida mais justa?

Os temas geradores de estudo captam a riqueza e radicalidade da EJA: Trabalho; Povos do Campo, Quilombolas e Indígenas; Direitos; Conhecimento; Cultura; Memória; Juventudes; Corpo. $\mathrm{Na}$ sua discussão, Arroyo retoma seus próprios trabalhos anteriores e se apoia principalmente em Paulo Freire com a ideia básica de valorizar os conhecimentos e a vida dos educandos oprimidos; no pensamento decolonial de Quijano, que ensina a radicalizar a análise das nossas condições de subalternizados; além de Boaventura Santos que levanta questões para vincular direitos humanos e educação.

Para cada um dos temas são levantados subtemas considerados pontos a privilegiar nos currículos de formação de educadores e educandos. Eles estão organizados em textos-análise seguindo uma complexa sequência de problematização: mostram os adolescentes, jovens e adultos ao mesmo tempo como sujeitos, vítimas da desigualdade e da segregação socioeconômica, resistentes, lutadores, criadores de outras identidades, e apontam a necessidade de se aprender com eles e de usar esta aprendizagem para a formação.

Dessa forma, os textos têm os passageiros e seus itinerários humanos-desumanos como centro atravessados por discussões sobre Formação Docente, Currículo, Práticas Pedagógicas, Avaliação, sempre a partir de problematizações e questionamentos com os quais resumo os temas a seguir. Estar mais atento às perguntas do que às repostas provoca o pensamento e novos questionamentos, que só serão respondidos nos contextos e nos coletivos dos quais participamos, em momento de criação; com criatividade, como ressalta Arroyo.

Se a EJA condensa processos tensos de construção e desconstrução de identidades coletivas, como ignorá-los nos currículos de formação e de educação destes coletivos identitários? Que artes pedagógicas seus educadores que formação, que docência, que material didático ajudará os educandos e os educadores a entenderem-se herdeiros de tantas resistências históricas formadoras de culturas, valores e identidades coletivas e a recuperar a humanidade roubada dos educandos?

Com perguntas como estas os temas vão sendo discutidos. Seguem outras, literais e provocadas pela leitura: 
Se o trabalho é estruturante do viver-sobreviver dos educandos e educadores, de sua identidade social, de classe, não deverá ser o trabalho estruturante do currículo, da proposta pedagógica?

Com que pedagogias acompanhar a história de precarização, exploração e resistência dos movimentos sociais e de trabalhadores?

Como não repetir esses percursos sociais e escolares segregadores nas práticas da EJA e das escolas?

O que podemos aprender com a forma como os trabalhadores sem terra, indígenas, quilombolas resistem e criticam radicalmente a forma como foram pensados e espoliados dos direitos à terra, ao trabalho e à educação?

Que postura ética adotar diante das injustiças escolares que reforçam injustiças sociais? A formação ética tem lugar?

Como formar profissionais que entendam os processos de interiorização e de destruição de identidades com que jovens e adultos voltam à escola depois de sucessivas reprovações? E como assumir como função pedagógica a reconstrução destas identidades?

Como lidar com o autoritarismo das avaliações nacionais, estaduais, internacionais que impõem as mesmas provas, critérios, resultados e classificações, independente das reconhecidas diferenças de classe, etnia, raça, campo, periferia, pobreza que chegam à EJA?

Não teríamos que reconhecer como violência obrigar os sujeitos produtores de conhecimento a aprender como únicos os conhecimentos escolares?

Estaria na cultura um dos desencontros entre docentes e discentes? Os primeiros se vendo como responsáveis pelo conhecimento e a cultura no contexto civilizatório e os segundos se vendo excluídos deste processo justamente pela violência que ele simboliza?

Haverá lugar nos currículos para dar centralidade à dimensão pedagógica e formadora da memória de jovens-adultos sobre processos de precarização-expropriação da terra, do espaço, da linguagem, do poder para desconstruir memórias negativas, desumanizantes e valorizar memórias de resistência humanizantes?

Que artes, que pedagogias de afirmação do direito à vida de adolescentes-jovens ameaçados deste direito cotidianamente usar? 
O que aprender, rever dos corpos ausentes de crianças, adolescentes, jovens e adultos $e$ idosos populares que vão chegando? Que lembranças têm de como seus corpos foram pensados, tratados nas escolas? Como trata-los?

Além de ser discutido a partir dessas e outras indagações, cada tema termina com a apresentação de letras de música, indicação de filmes, obras literárias e outras músicas que podem ser usadas para trabalhar o tema em questão, com o objetivo de incorporar a força pedagógica das artes, constantemente apresentada no livro como forma de conhecimento de si e de humanização.

Em conformidade com o permanente esforço de Arroyo em nos ensinar a aprender com os movimentos sociais, os textos-análise valorizam experiências, saberes-vivências-indagações de educadores e seus coletivos, em projetos de escolas e redes públicas que produzem suas propostas pedagógicas. Embora não fique claro onde estão e quem são, suas propostas são colocadas em contraponto com documentos oficiais que expressam o pensamento político-pedagógico hegemônico, e são continuamente destacados seus avanços em reconhecer os educandos como sujeitos de direitos e entender suas vivências permeadas pela injustiça social.

Ao provocar o pensamento sobre possibilidades de fazer escolhas pedagógicas outras, que problematizem a vida e por isso contribuam para compreender a injustiça e a desigualdade das formas de organização do mundo e seus "padrões de poder e de trabalho, de propriedadeapropriação da terra, da renda tão sexistas, classistas, racistas" (p.28), esta obra contribui para o enfrentamento das tentativas de aprofundar as injustiça e desigualdades que os passageiros (sujeitos educandos e educadores da EJA) vivem, principalmente com os efeitos do golpe midiáticoparlamentar de 2016, já considerados no livro. Por isso, é uma proposta de repolitizar a EJA, dando aos jovens e adultos o direito de saberem-se nesse retrocesso que condiciona seus direitos de trabalhadores e cidadãos. Pobreza, miséria, subemprego, desemprego, trabalho provisório, incerto, informal, tempos incertos de trabalho: traços do trabalho contemporâneo. Como trabalha-los na diversidade das áreas de conhecimento? Que EJA é possível em tempo de precariedade e insegurança dos direitos do trabalho e da cidadania?

O livro nos mobiliza a superar um paradigma epistemológico-pedagógico hegemônico criando outro paradigma político-pedagógico, e nos ajuda a entender que um currículo nacional não dá conta da diversidade, da radicalidade, da complexidade, dos saberes, da história dos coletivos populares, entre outros motivos porque não dá espaço a perguntas, como faz o autor. Assim, seus textos constituem-se em leitura e discussão imprescindível nos componentes curriculares que discutem EJA na formação docente. 


\section{REFERÊNCIA}

ARROYO, Miguel G. Passageiros da Noite: do trabalho para a EJA : itinerários pelo direito a uma vida mais justa. Petrópolis, RJ: Vozes, 2017. 